\title{
Archives of Urology
}

ISSN: 2638-5228

Volume 1, Issue 2, 2018, PP: 48-51

\section{Vesical Extrophia and Pregnancy. Case Report}

\author{
Prof. Dr. Illia R.H. MD. FACOG ${ }^{1 *}$, Drs. Guallan F. ${ }^{2}$, Codoni M.J. ${ }^{2}$, Bianchi F. ${ }^{3}$, Uranga Imaz ${ }^{4}$ \\ Lobenstein $\mathbf{G}^{4}$, Manrique Guido ${ }^{4}$, Fiameni $\mathrm{F}^{4}$ \\ ${ }^{1}$ Professor of Obstetrics at Medicine School, Buenos Aires University, Argentine. \\ Chief of Obstetrics Service at German Hospital, Bs. As. Argentine. \\ FACOG, Buenos Aires Argentine Section, President: Prof. Dr. Oscar Contreras Ortiz. \\ ${ }^{2}$ Residents of Obstetrics Service. \\ ${ }^{3}$ Oncology Surgeon, Gynecology Service, German Hospital, Bs. As. Argentine. \\ ${ }^{4}$ Obstetrical Staff, Obstetric Service, German Hospital, Bs. As. Argentine. \\ Obstetrics Service, Hospital Alemán, Buenos Aires, Argentine. \\ *rillia@gmail.com-fax
}

*Corresponding Author: Prof. Dr. Ricardo Illia, Professor of Obstetrics at Medicine School, Buenos Aires University, Argentine.

KEYWORDS: vesical extrophy, enterocistoplastic surgery, pregnancy, urinary tract reconstruction, Mitrofanoff technique.

\section{BACKGROUND}

There are few published cases of enteroplastic surgery to repair vesical extrophia and pregnancy with Mitrofanoff technique. Usually, the pregnancy is not affected by the new bladder, but the problem is the way to delivery according the technique used to correct it. In this cases, the delivery of a fetus is recommended by scheduled CS as close to term as possible to avoid damage of the plastic surgery over the bladder or new bladder. A search in pubMed allow us find only 4 reports about this subject. Vesical extrophy (VE) is a defect in anterior midline of low abdomen with several types and involve abdominal wall bellow the umbilicus including pelvis, urinary tract and external genitalia. The main complication is to open urinary bladder to external environment. (1-2)

The reported prevalence is from 1 in 30.000 to 1 in 50.000 live newborns (3).

There is a risk of recurrence of 0.5 to $0.3 \%$ in families with only one relative affected. No ethiological factor neither genetical nor no genetical factor has been identified until the present time, however, there are some chromosomical areas related with VE that are at the beginning of the identification.

There are few information about fertility of women who underwent to this surgical correction during their childhood, as well as about of consequences attributable to a pregnancy in this cases and mainly the way of delivery suggested(4).

CASE

We expose the case of a pregnant woman, first pregnancy, 29 years old, with bladder congenital extrophya, corrected with plastic surgery consisted in enterocistoplastic union and urinary derivation with Mitrofanoff technique, with placenta previa occlusive (PPOT). Pregnant woman, 29 years old, first spontaneous pregnancy, one fetus, with congenital VE corrected during her childhood with several surgeries and finally solved with a Mitrofanoff technique. She underwent to multiple surgeries during her adolescence because urinary fistulaes and stones in their urinary tract.

In april 30 of 2015, she underwent to laparoscopic surgery because stones in her urinary tract.

The pregnancy was uneventfull, with monthly urine cultures and several urinary infections treated with oral antibiotics.

She developed vesico-cutaneous fistulae in low abdomen at 25 week's of gestational age. By ultrasound we confirmed the presence of occlusive previa total placentae.

During their third trimester we performed several intermitent catheterizations and finally decided to instale a permanent vesical Foley. She developed 
more urinary infections treated with antibiotics and was indicated by urologists nitrofurantoine prophylaxis with a $100 \mathrm{mg}$ daily oral dose. At 34 week's of gestational age she started with vaginal bleeding. She was admitted at hospital and we started fetal lung maturation induction with betametasone in the habitual scheme. At 48hs after admssion she stoped bleeding and was discharged, scheduling CS for 36 week's. The problem was to decide the place of incisión because all anterior abdomen wall was occupied by the new urinary bladder and by lateral places we presumed the risk to damage the ureters.
While she was at hospital we performed a magnetic nuclear resonance (MNR) without contrast to evaluate the possible way of access to the womb. The inform was: bladder wided according surgical background with Mitrofanoff technique. The bladder is between the womb and the anterior abdominal wall with estimated $18 \mathrm{~cm}$ length. About in the middle of this extensión, $4 \mathrm{~cm}$ below of the Foley orifice we can observe a vesical fistulae connected with the skin, of $13 \mathrm{~cm}$ length. An image that could be a stone was watched into the bladder behind the previous image (Fig 1).

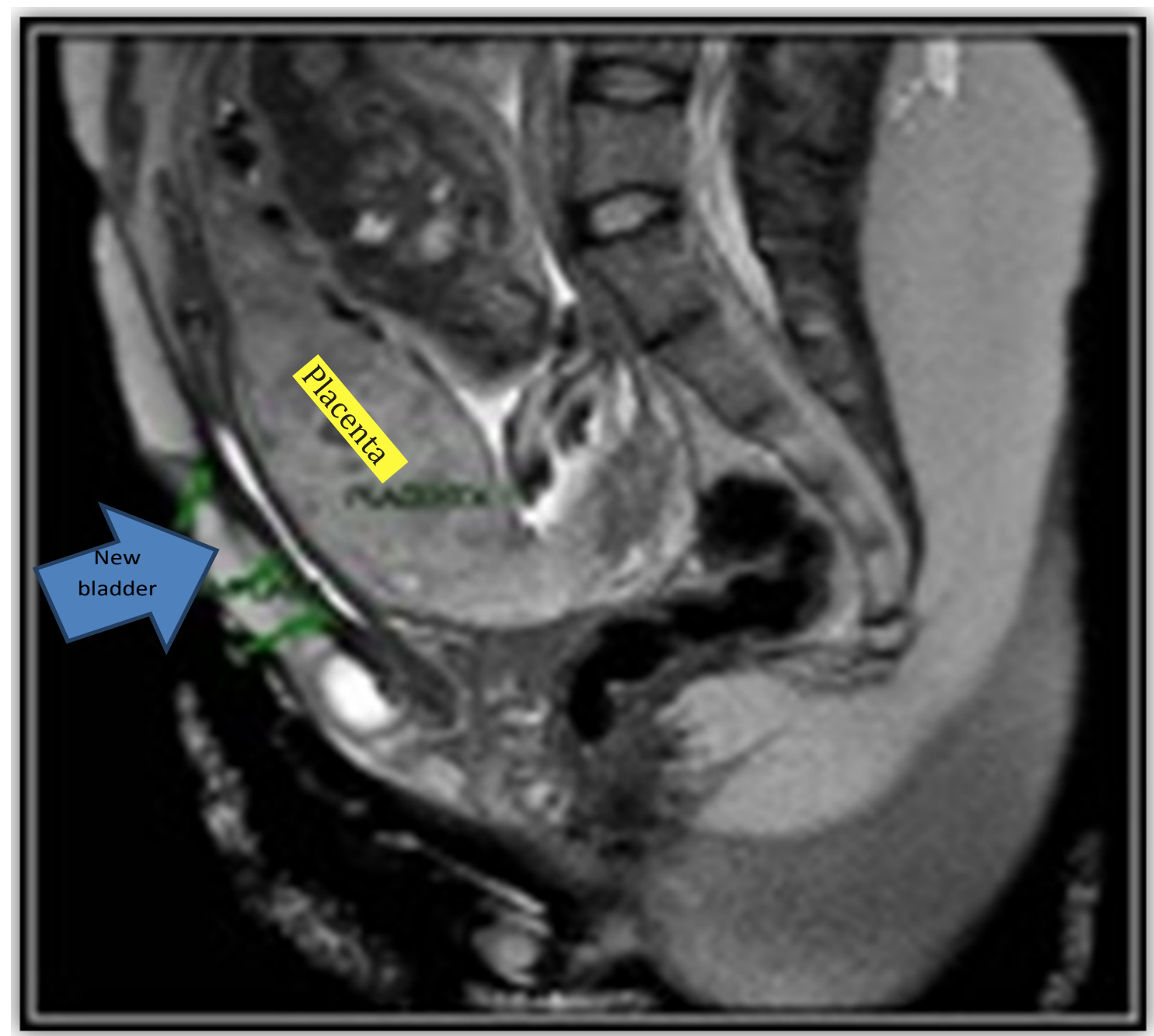

Figure 1. We can observe anterior to the womb the new bladder made with gut, the Placenta previa and the fetus in transverse situation (MNR).

At december 7 of 2015, with 35.6 week's of gestational age, the patient start to bleed again and we decided to perform a CS. The way of access to abdomen was by transverse section over the umbilicus and below the ribs with fundal histerotomy (Fig 2-3) and extraction of a new born fetus, male sex, weighing 2.640g Apgar score 9/10.

The postoperatory evolution of the patient was uneventfully and was discharged after three days (Fig 4). 


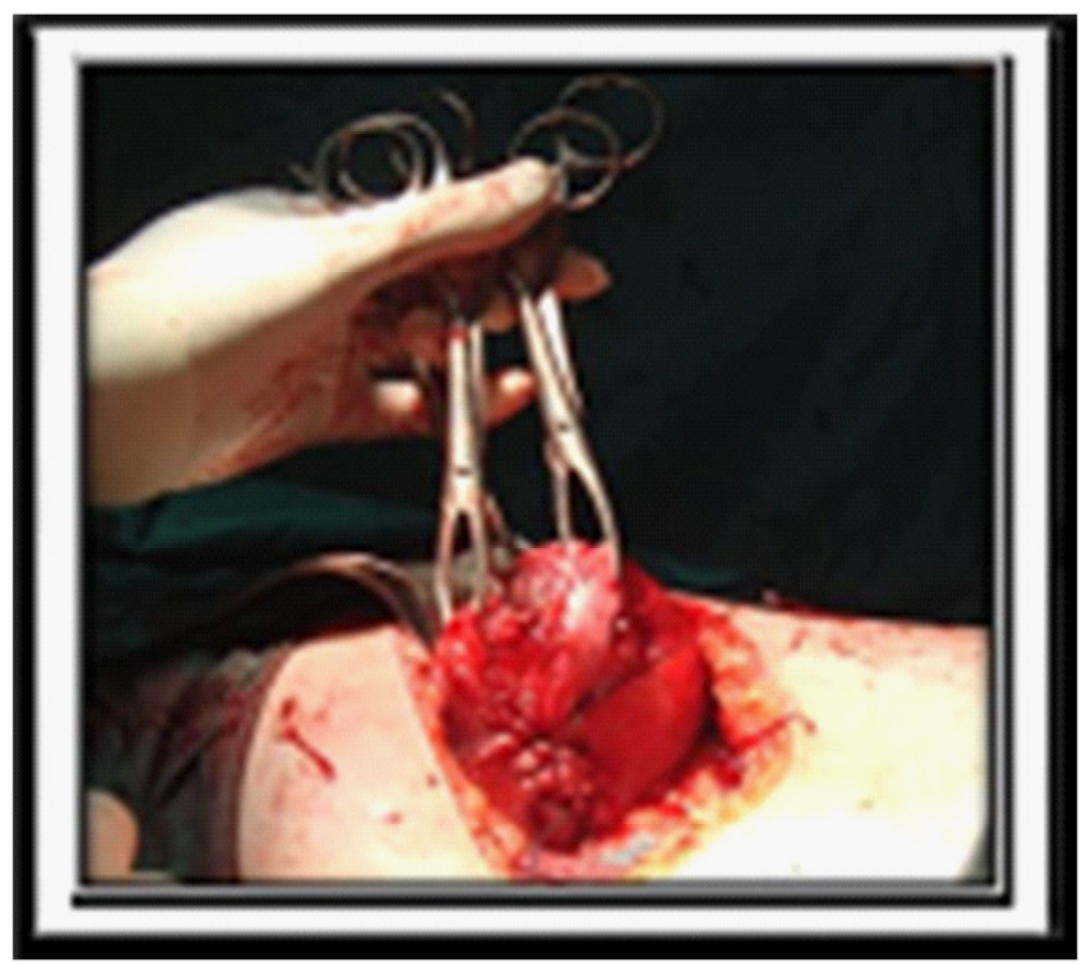

Figure 2. Transversal fundal hysterotomy.

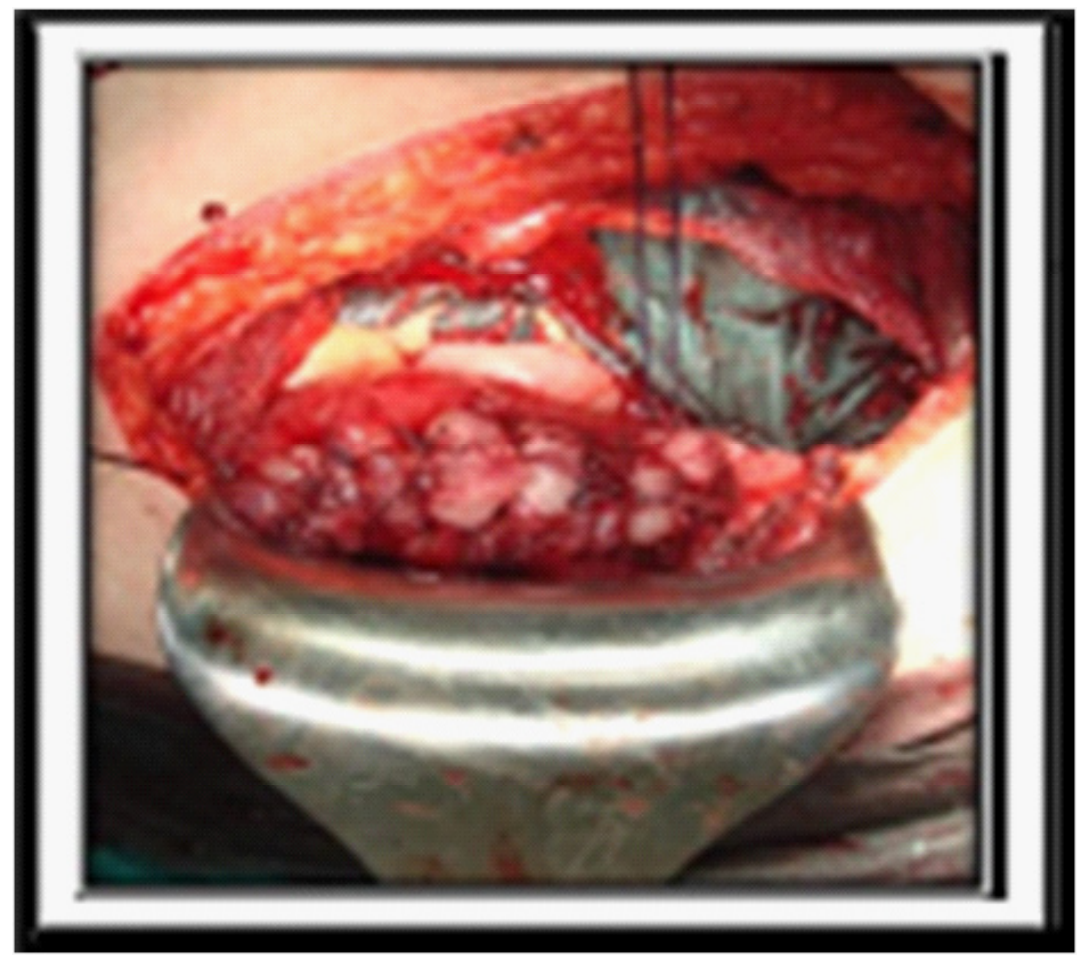

Figure 3. Transversal fundal hysterotomy closed

\section{DISCUSSION}

Neither the pregnancy nor the plastic reconstruction with Mitrofanoff technique were affected by the pregnancy. Also, the kidney function was not affected in patients with correction of congenital anomalies of urogenital tract according the few information we have got (4). There were a very high rate of breechs (57\%) and high rate of urinary tract infections (53\%). There 
were obstruction in the high part of the urinary tract that nedeed intervention (10\%) and preeclampsia (10\%). A third of the term pregnancies in this group of patients, developed as a complication a cord prolapse near to term after the rupture of membranes(1). The pregnancy control after 20 week's should be every two week's until 28 week's, with ultrasound evaluation of urinary tract modifications, urinary tests and cultures.

Vaginal delivery trend to impair the genital prolapse being more difficult to treat and delivery should be performed by scheduled CS as close as posible to 37 week's of gestational age with steroids administration(1).

\section{ConClusion}

Women with urogenital plastic reconstruction of congenital anomalies are fertil, they have normal pregnancies and healthy newborns. There are a need of following and interventions during pregnancy because a high rate of urinary tract infections, preeclampsia, high urinary tract obstruction and breechs. In general context, it is recommended to end the pregnancy by scheduled CS before the start of labour. The work with a team made up by obstetricians, perinatologists, urologists and neonatologists is desirable to achieve an succesfull outcome in this very few frecuent complication of pregnancy.

\section{REFERENCES}

[1] Prenatal diagnosis of covered cloacal extrophy. Mallmann M, Reutter H, Muller A, Boemers T, Geipel A, Berg C, Gembruch U. Fetal Diagn Ther 2014; 36 (4): 333-6.

[2] Pregnancy after lower urinary tract reconstruction for congenital abnormalities. Greenwell T, Venn S, Creighton S, Leaver R, Woodhouse C. BJU int 2003; 92: 773-7.

[3] Pregnancy in a case with vesical extrophy and renal insufficiency. Sikora S, Siekierski B, Eechout P. Ginekol Pol 1998; 69: 603-6.

[4] Extrophy of the bladder and pregnancy. Body G, Lagsac J, Lanson Y, Berger C. J Gynecol Obstet Biol Reprod 1984; 13: 549-55.

Citation: Prof. Dr. Illia R.H., Drs. Guallan F., Codoni M.J., et al. Vesical Extrophia and Pregnancy. Case Report. Archives of Urology. 2018; 1(2): 48-51.

Copyright: (C) 2018 Prof. Dr. Illia R.H., Drs. Guallan F., Codoni M.J., et al. This is an open access article distributed under the Creative Commons Attribution License, which permits unrestricted use, distribution, and reproduction in any medium, provided the original work is properly cited. 